\title{
Only children or siblings: Who has higher physical activity and healthier weight?
}

\author{
Erik Sigmund ${ }^{\varpi}$ and Dagmar Sigmundová \\ Institute of Active Lifestyle, Faculty of Physical Culture, Palacký University Olomouc, Czech Republic
}

\begin{abstract}
Background: The influence of parents on physical activity (PA) and body weight of their children is confirmed by scientific studies. However, it is not known whether only children or those with siblings have a higher level of PA and healthier body weight. Objective: The aims of this study are (i) to assess whether there are any differences in the achievement of the daily step count (SC) recommendation and in the prevalence of overweight/obesity between only children and children from families with multiple children, and (ii) to investigate whether the achievement of the SC recommendation by children/parents and parental overweight/obesity is associated with childhood obesity. Methods: The analysis included 566 families (10.6\%/89.4\% with single child/two or more children) with complete data on weight status and PA monitored with a Yamax pedometer during regular school/work between 2013-2019. The daily SC recommendation amounted to $\geq 13,000 / 11,000$ SC for 5-12-year-old sons/daughters and $\geq 10,000$ SC for 12-16-yearold adolescents and adults. The chi-square test was used to compare the achievement of the daily SC recommendation and the prevalence of overweight/obesity. Binary logistic regression analyses were used to investigate whether the achievement of the daily SC recommendation by children/parents and parental overweight/obesity were associated with obesity in their offspring. Results: A significantly higher proportion of children with siblings achieved the recommended daily SC $(51.8 \% \mathrm{vs.} 31.7 \%, p=.003)$ and showed a lower prevalence of overweight $(16.2 \%$ vs. $20.0 \%, p=.041)$ and obesity $(7.1 \%$ vs. $20.0 \%, p<.001)$ compared with only children. The achievement of the daily SC recommendation in children significantly $(p<.05)$ decreased the odds ratio of obesity (odds ratios $0.22-0.34,95 \%$ confidence intervals $0.07-0.85)$. Conclusions: Children from families with siblings had higher physical activity and healthier body weight than those from single-child families. However, reaching the recommended daily SC reduces the likelihood of childhood obesity, regardless of the presence of a sibling in the family.
\end{abstract}

Keywords: step counts, obesity, parent, only child, siblings, weekend

\section{Introduction}

Childhood obesity arises as a result of the interaction between a complex of genetic, environmental, and psychosocial determinants that lead to excessive food intake and insufficient physical activity (PA; Baranowski et al., 2019). Behavioural individual or family-based energy balancerelated changes in diet and PA are currently the primary tools for modifying lifestyles and preventing childhood obesity. However, they show a rather small and short-term effect and a high level of heterogeneity (Al-Khudairy et al., 2017; Mead et al., 2017). Weight loss and post-weight loss maintenance are difficult to achieve, and the long-term application of multi-component obesity-reducing interventions of proven efficacy in the short term tends to fail in real life (Beets et al., 2019). Thus, from a public health perspective, there is still a relevant demand for identifying the determinants and correlates of childhood obesity in real-life conditions to formulate preventive recommendations and design effective interventions.
Naturally, research on children's energy balance-related behaviours frequently focuses on the family lifestyle and environment. The family is the setting where the first longterm formation of the dietary and PA patterns of children occurs, and family-based lifestyle interventions are still the cornerstone of weight management in children (Kumar $\&$ Kelly, 2017). In general, there is a positive correlation between parent-child body weight status and the risk of child obesity when their parents are obese (Bushnik et al., 2017; Liu et al., 2013). Similarly, positive associations between the PA of parents and their children have been observed repeatedly (Craig et al., 2013; Sigmundová et al., 2020). However, findings on parent-child relationships in PA and obesity relative to the number of children in the family are scarce.

Many family-related determinants and correlates of childhood obesity have been uncovered in genetics (e.g., parental overweight), lifestyle (e.g., parental stress, maternal smoking or breastfeeding status), or sociology (e.g., the socioeconomic status of families; Danielzik et al., 2004; Parks et al., 2012), but there are still incomplete and

$\triangle$ Corresponding author: Erik Sigmund, e-mail erik.sigmund@upol.cz, ORCID® record https://orcid.org/0000-0002-5643-5586

Article history: Received December 8 2020, Accepted April 21 2021, Published April 262021

Copyright: @ 2021 The Author(s). Published by Palacký University Olomouc. This is an open access article distributed under the terms of the Creative Commons Attribution License (https://creativecommons.org/licenses/by/4.0/), which permits unrestricted use, distribution, and reproduction in any medium, provided the original author and source are credited. This license does not cover any third-party material that may appear with permission in the article. 
inconsistent findings regarding the family environment and parenting styles in relation to childhood obesity (Appelhans et al., 2014; Kakinami et al., 2015). One of the reasons for the inconsistency between some parental variables and childhood obesity may stem from a change in the structure of families with children in economically developed countries over the past two decades - an increase in the age of mothers at their first pregnancy and the growing number of single-child families (Glinianaia et al., 2008; Hašková et al., 2019).

From a psychosocial point of view (psychological distress, susceptibility to negative peer pressure, self-reported school performance, and problem behaviours), only children do not differ from children with siblings, however, there are possible indications of differences in the level of PA depending on the number of siblings (Hallal et al., 2006; McMinn et al., 2013). For example, growing up in a family with multiple children provides opportunities for engaging in playing and being more physically active, regardless of the birth order of the siblings. Hence, such increased PA might partly explain the observed protective effects of larger sibships (Hallal et al., 2006).

This study attempts to bridge the research gap with information concerning a comparison of lifestyle indicators between single-child families and families with multiple children. One aim of this study is to assess whether there are any differences in the achievement of the daily step count (SC) recommendation and in the prevalence of overweight and obesity between only children and children from families with multiple children. Another aim is to investigate whether the achievement of the daily SC recommendation by children/parents and parental overweight/obesity are associated with childhood obesity.

\section{Methods}

\section{Participants and inclusion/exclusion criteria}

Participants were recruited by means of two-stage stratified random sampling. In the first stage, nine out of 14 administrative regions, three of each in the lowest, middle, and highest terciles for gross domestic product in Czechia, were randomly selected. In the second stage, seven public kindergartens located in urban areas and three in rural locations and 36 public primary schools located in urban areas and 15 in rural locations were randomly selected. Private schools/kindergartens were not addressed because public schools/kindergartens prevail strongly, and the number of private schools/kindergartens is still negligible in Czechia (Rojíček et al., 2019).

Invitation letters were mailed/sent to 2,389 families, of whom $65.3 \%$ agreed to take part in the research (written informed consent received). The participating children and their parents were predominantly white Caucasian (> 98\%), which is representative of the ethnic demographics of the Czechia (Rojíček et al., 2019). The family dyads consisted of a mother-child or father-child couple. The participation of at least one family dyad was a necessary precondition for being included in the research. In the initial stage of the study, information meetings were held to describe the process of the research. Research data was received from 1,325 family dyads (811 mother-child dyads and 514 father-child dyads), and 89 distant relatives, grandmothers, teachers, etc., who were excluded from the study. Of the total number of parent-child dyads, 541 dyads were excluded because of non-compliance with any of the following criteria: a) children $<4$ years old or $\geq 16$ years old $(n=151)$, b) missing data about body height or weight $(n=106)$, c) pedometer wearing time $<8 \mathrm{hr} /$ day or step count data that covered less than four working days and one weekend day $(n=91)$, d) missing sibling data $(n=193)$. The final dataset included 784 family dyads ( 474 mother-child dyads and 310 father-child dyads) with complete anthropometric data, step count data, and family type data. The basic anthropometric characteristics of the parent-child dyads are depicted in Table 1.

\section{Procedures and measurement}

After recruitment and submission of a written consent, each family received a self-monitoring package including: 1) a letter describing the study design and the ethical approval, 2) a family logbook for recording the anthropometric and PA data of all family members, 3) Yamax Digiwalker SW-200 (Yamax Corporation, Tokyo, Japan) pedometers for each participating child and parent, 4) a detailed and illustrated guide describing how to operate the pedometer, 5) an explanatory letter to the teachers/coaches about the study explaining why a pedometer is worn by children during lessons/training, and 6) an illustrated instruction leaflet for home measurement of the body weight and height of the family participants (Sigmund \& Sigmundová, 2017).

To maintain the comparability of the family-related PA data with previous studies (Sigmund \& Sigmundová, 2017; Sigmundová et al., 2020), the use of the Yamax Digiwalker SW-200 pedometer and the family logbook for recording the anthropometric and PA data of all family members was

Table 1 Basic anthropometric characteristics (as $M(S D)$ ) of final parent-child dyads separately for single-child families and families with more children and gender of parents

\begin{tabular}{lccc}
\hline \multicolumn{1}{l}{ Characteristics } & \multicolumn{1}{l}{ Children } & Mothers & \multicolumn{1}{c}{ Fathers } \\
\hline Single-child families (60 families, 51 mother-child dyads, 36 father-child dyads) & \\
Calendar age (years) & $9.47(2.39)$ & $39.27(4.99)$ & $42.01(5.05)$ \\
Body mass index $\left(\mathrm{kg} / \mathrm{m}^{2}\right)$ & $18.07(3.36)$ & $23.29(3.49)$ & $27.11(3.52)$ \\
Families with more children (506 families, 423 mother-child dyads, 274 father-child dyads) & \\
Calendar age (years) & $10.79(2.76)$ & $40.72(4.62)$ & $42.98(5.75)$ \\
Body mass index $\left(\mathrm{kg} / \mathrm{m}^{2}\right)$ & $18.03(3.37)$ & $23.91(3.72)$ & $27.37(3.71)$ \\
\hline
\end{tabular}


retained. The Yamax Digiwalker SW-200 pedometer is an unobtrusive, simple, valid, and reliable quantifier of all-day ambulatory PA across a wide population of children, adolescents (Rowlands \& Eston, 2007), and adults (Kooiman et al., 2015) designed for an analysis of the relationship between daily SC and health outcomes (Basett et al., 2017). The participants were asked to wear the pedometer attached to their right hip for eight consecutive days throughout the whole day and record their daily SC and possible active participation in organized leisure-time sport in the family logbook that was provided. The parents recorded whether they or their children actively participated in organized leisure-time sports/activities lasting longer than 20 minutes. Organized leisure-time activities included sports, training, arts, and hobby clubs attended outside school/paid employment (Sigmund \& Sigmundová, 2017).

The SC data from the first day of PA monitoring was not included in the final analyses because of the novelty of wearing the pedometer, which might have affected the level of the participants' PA (Rowe et al., 2004). The parents and children were instructed to wear the pedometer throughout the whole day (during their journey to school/ work, during classes and breaks, and during participation in organized leisure-time sport or leisure organizations) except when dressing, performing personal hygiene, and showering/bathing. The elimination of seasonal differences was sought by choosing spring and autumn months in weeks without excessive examinations in schools and without multi-day school holidays and public holidays (Sigmund \& Sigmundová, 2017).

The parents were asked to fill in the date of birth of child/children, calendar age of parents, gender, and anthropometric data (body height with $0.5 \mathrm{~cm}$ and body weight with $0.5 \mathrm{~kg}$ accuracy) of all the participating family members in the family logbook before the start of the eight-day SC monitoring. The parents were thoroughly instructed by the researchers how to measure their own body height and weight, as well as the height and weight of their offspring. In the enclosed instruction leaflet for home measurement of the body height and weight, the correct upright posture to the wall (barefoot) or the correct reading of the resulting body height was depicted. The body weight measurements were illustrated barefoot only in participants' underwear. Parental measurement of the body height and weight of their offspring at home seems to be a sufficiently valid method to identify overweight/obesity according to the calculated body mass index (BMI) compared with objective or laboratory/researcher measurements (Huybrechts et al., 2014; Chai et al., 2019).

\section{Ethics}

The study design, all procedures, and the measurement and method of feedback were approved by the Ethics Committee of the Faculty of Physical Culture, Palacký University Olomouc separately for families with preschool children (ref. No.: 57/2014 on 21 December 2014), families with 6-11-year-old children (ref. No.: 20/2012 on 12 December 2012), and families with 12-15-year-old adolescents (ref. No.: 14/2018 on 21 February 2018). The parents' written consent was obtained prior to the start of the data collection. Participation in the project was voluntary and without financial incentives.

\section{Data management}

Data management was conducted using IBM SPSS Statistics (Version 22 for Windows; IBM, Armonk, NY, USA). The BMI categories (underweight, normal weight, overweight, or obese) were derived using age- and gender-specific World Health Organization (WHO) growth charts (de Onis et al., 2007; WHO, 2007). Overweight and obesity in the children was represented by a BMI from the $85^{\text {th }}$ to $97^{\text {th }}$ and $>97^{\text {th }}$ percentile of the WHO growth charts, respectively (de Onis et al., 2007; WHO, 2007). Overweight and obesity in the parents was classified using a BMI from 25 $\mathrm{kg} / \mathrm{m}^{2}$ to $29.9 \mathrm{~kg} / \mathrm{m}^{2}$ and greater than or equal to $30 \mathrm{~kg} / \mathrm{m}^{2}$, respectively (WHO, 2014).

The daily step count variable represented the mean difference between the morning (pedometer turned on) and evening (pedometer turned off) step counts on the days of the week that were monitored. Daily SC values below 1,000 and above 30,000 were truncated to these recommended values, respectively (Rowe et al., 2004), and included in the analyses. If step counts were recorded during four weekdays, data for the one missing weekday that was based on the participant's personal mean scores was added. The participants whose step count data was missing for more than one day were excluded from the analysis. The average daily SC was calculated separately for school/workdays and for weekends as the sum of the individual daily SC divided by the number of days. The daily SC recommendation was set at a value of $\geq 13,000 / 11,000$ steps/day for 5-12-year-old sons/daughters and $\geq 10,000$ steps/day for 12-16-year-old adolescents (Tudor-Locke, Craig, Beets, et al., 2011) and adults (Tudor-Locke, Craig, Brown, et al., 2011).

\section{Statistical analysis}

Because of previous differences in the relationships between the PA of mothers/fathers and their offspring (Sigmund \& Sigmundová, 2017; Sigmundová et al., 2020), all statistical analyses were done separately for mother-child and father-child dyads. The percentage of achievement of the recommended daily SC by individual family members was quantified separately for school/workdays, weekends, and the whole week. The Pearson's chi-square test was used to compare the prevalence of obesity, overweight, normal body weight, and underweight, achievement of the daily SC recommendation, and frequency of participation in organized leisure-time sport between the single children and children with siblings.

Neither the Shapiro-Wilk test nor the KolmogorovSmirnov test confirmed the normal distribution of SC variables. As a result of the non-normal distribution of SC variables, the Mann-Whitney $U$ test was used to compare workday and weekend SC. The parent-child daily SC or BMI relationship was quantified using the Spearman's correlation coefficient. Binary logistic regression analyses (Enter method) were used to investigate whether the achievement of the daily SC recommendation by children/parents and 
parental obesity and living in single-child families or families with more children (as the independent variables) were associated with the obesity of offspring (as the dependent variable). The results of the logistic regression analyses were expressed using the odds ratio $(O R)$ and $95 \%$ confidence interval (CI). All statistical analyses were conducted using IBM SPSS Statistics (Version 22 for Windows; IBM, Armonk, NY, USA). The alpha level of significance was set at the minimum value of .05 .

\section{Results}

The children who had at least one sibling had a significantly higher percentage of compliance with the recommended daily SC at weekends ( $43.1 \%$ vs. $23.3 \%, p=.003$ ) and as a weekly average $(51.8 \%$ vs. $31.7 \%, p=.003)$ compared with only children (Figure 1). The children with siblings had a healthier body weight than the children from single-child families. In particular, the children with siblings showed a lower prevalence of overweight (16.2\% vs. $20.0 \%, p=.041)$ and obesity $(7.1 \%$ vs. $20.0 \%, p<.001)$ and, analogously, a higher proportion of normal body weight $(71.1 \%$ vs. $56.7 \%, p=.022)$ than the only children (Figure 1).

The children with a sibling significantly $(p=.049)$ exceed the only children in their daily weekend SC. Similarly, in the mothers of children with siblings a significantly ( $p=.018$ ) higher daily SC at weekends was observed compared with the mothers of only children (Figure 2). The absence of participation in organized leisure-time sport was recorded in $40.7 \%$ of the single children and $34.7 \%$ of the children from families where there were siblings $(p=.031)$.

Figure 1 Comparison of achievement of daily recommended step counts (SC) and body weight levels (\%) for children from single-child families and families with at least two children

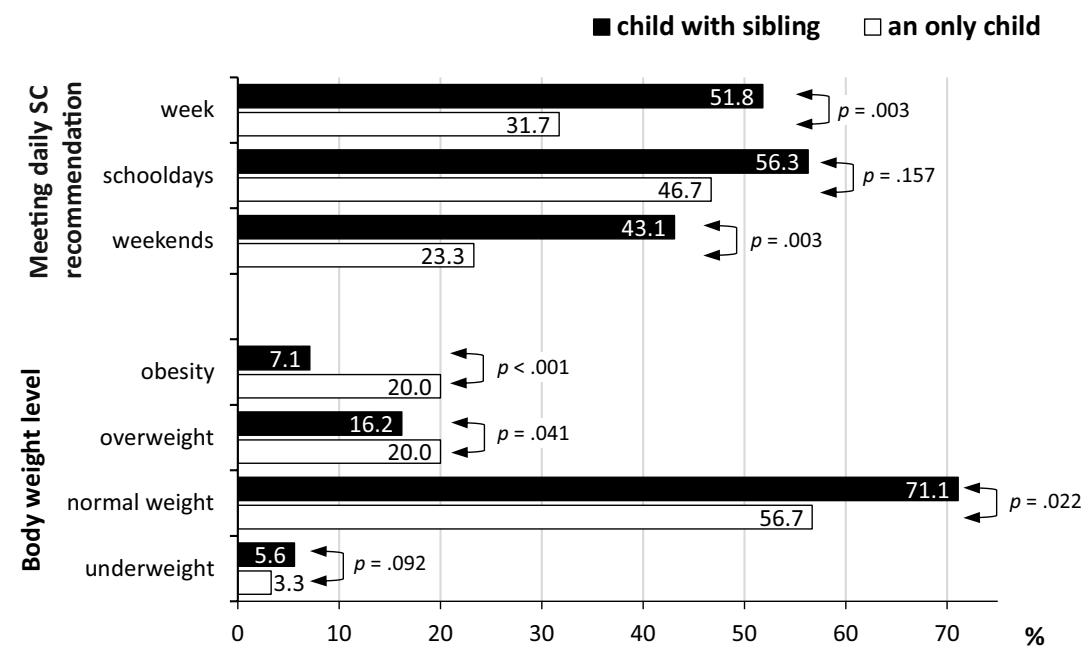

Figure 2 Comparison between family members of parents' and children's pedometer-determined daily step counts (median, interquartile range) on workdays and weekend days in families with at least two children and with a single child

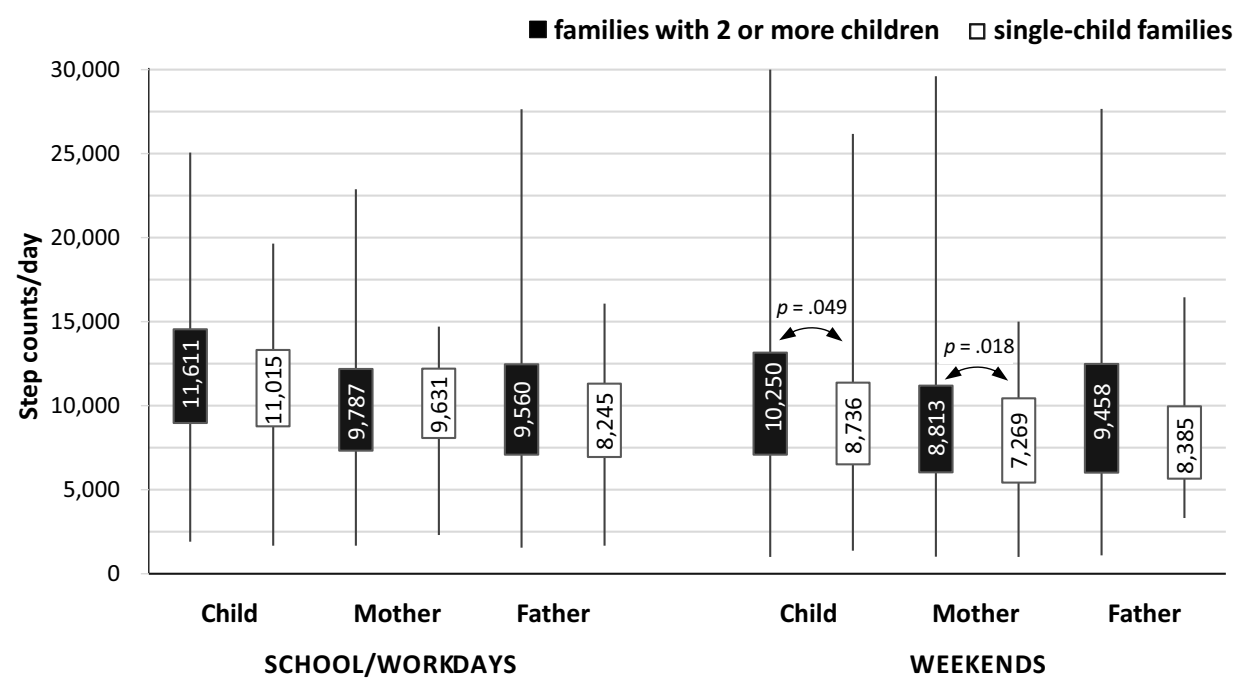


There was a significant correlation between daily SC of parents and children in families with more children ranging from .20 to .29 (Table 2).

Positive relationships between the BMI of parents and of their children were found in both single-child families and families with multiple children. In addition, among children with a sibling we observed a negative correlation between the mean daily SC for week and working days long monitoring and BMI $\left(r_{\mathrm{S}}=-.13, p=.003\right.$ for weekly SC; $r_{\mathrm{S}}=-.16, p<.001$ for working days SC).

The achievement of the recommended daily SC by children was associated with significantly lower odds of obesity in all the models presented (Table 2). The odds of obesity occurring in the children with siblings were half those of the only children; this was, however, only significant for mother-child dyads (OR $0.41 ; 95 \%$ CI $[0.18,0.91])$ in the PA model not adjusted for parents' weight. Excessive body weight of mothers was associated with the occurrence of obesity in their children (Table 3).

\section{Discussion}

The present study reveals the fundamental differences in the prevalence of overweight, obesity, and daily PA between the children with siblings and only children. The children with siblings have a "healthier" body weight and achieve the recommended all-day PA more often than the only children. In addition, in the families with more children, there seems to be a closer relationship between the PA of the parents and their children. However, the achievement of the recommended daily amount of PA is associated with lower odds of obesity regardless of the number of offspring in the family.

PA, represented by the daily SC, is higher for all family members on school/working days than on weekend days, regardless of the number of children in the family. However, a greater decrease in the amount of PA on weekend days compared with school days is observed in the members of single-child families (child -1,776 steps per day, mother/ father: $-2,270 /-764$ steps per day). Although it seems that it should be easier for single-child families to organize and implement PA to a greater extent than is the case with families with more than one child, this is not the case. This reasoning is supported by the lower correlation coefficients for parent-child daily SC found in the single-child families compared with the families with more than one child. The school regime, together with participation in organized leisure-time sports for children and a paid employment

Table 2 Parent-child correlations in daily step counts and body mass index for children from single-child families and families with two or more children

\begin{tabular}{|c|c|c|c|c|c|c|c|c|}
\hline \multirow[b]{3}{*}{ Type of family } & \multicolumn{6}{|c|}{ Daily step counts } & & \\
\hline & \multicolumn{2}{|c|}{ Week } & \multicolumn{2}{|c|}{ Workdays } & \multicolumn{2}{|c|}{ Weekend } & \multicolumn{2}{|c|}{ Body mass index } \\
\hline & Mother & Father & Mother & Father & Mother & Father & Mother & Father \\
\hline \multicolumn{9}{|c|}{ Single-child (60 families) } \\
\hline$r_{\mathrm{s}}$ & .19 & .10 & .14 & .04 & .23 & .31 & .32 & .38 \\
\hline $95 \% \mathrm{Cl} r_{\mathrm{s}}$ & {$[-.07, .42]$} & {$[-.16, .35]$} & {$[-.12, .38]$} & {$[-.22, .29]$} & {$[-.03, .46]$} & {$[.06, .52]$} & {$[.07,0.53]$} & {$[.14, .58]$} \\
\hline$p$ & .184 & .545 & .332 & .836 & .102 & .068 & .041 & .032 \\
\hline \multicolumn{9}{|c|}{ With more children (506 families) } \\
\hline$r_{\mathrm{s}}$ & .21 & .29 & .20 & .23 & .25 & .27 & .28 & .34 \\
\hline $95 \% \mathrm{Cl} r_{\mathrm{s}}$ & {$[.13, .29]$} & {$[.21, .37]$} & {$[.12, .28]$} & {$[.15, .31]$} & {$[.17, .33]$} & {$[.19, .35]$} & {$[.20, .36]$} & {$[.26, .41]$} \\
\hline$p$ & $<.001$ & $<.001$ & $<.001$ & $<.001$ & $<.001$ & $<.001$ & .011 & .009 \\
\hline
\end{tabular}

Table 3 Association $(O R$ and $95 \% \mathrm{Cl})$ between family lifestyle indicators and obesity of family offspring in mother/father-child dyads

\begin{tabular}{|c|c|c|c|c|c|c|c|c|}
\hline & \multicolumn{4}{|c|}{ Model with PA level } & \multicolumn{4}{|c|}{ Model with PA level and overweight/obesity of parents } \\
\hline & \multicolumn{2}{|c|}{ Mother-child } & \multicolumn{2}{|c|}{ Father-child } & \multicolumn{2}{|c|}{ Mother-child } & \multicolumn{2}{|c|}{ Father-child } \\
\hline & $O R$ & $95 \% \mathrm{Cl}$ & $O R$ & $95 \% \mathrm{Cl}$ & $O R$ & $95 \% \mathrm{Cl}$ & $O R$ & $95 \% \mathrm{Cl}$ \\
\hline \multicolumn{9}{|l|}{ Type of family } \\
\hline Single-child & Ref. & & Ref. & & Ref. & & Ref. & \\
\hline With more children & $0.41 *$ & {$[0.18,0.91]$} & 0.45 & {$[0.16,1.24]$} & 0.48 & {$[0.19,1.23]$} & 0.54 & {$[0.18,1.62]$} \\
\hline \multicolumn{9}{|c|}{ Children's step counts recommendation } \\
\hline Not achieved & Ref. & & Ref. & & Ref. & & Ref. & \\
\hline Achieved & $0.34 * *$ & {$[0.17,0.71]$} & $0.32 *$ & {$[0.12,0.85]$} & $0.28 * *$ & {$[0.12,0.64]$} & $0.22 *$ & {$[0.07,0.68]$} \\
\hline \multicolumn{9}{|l|}{ Parental step counts } \\
\hline$<10,000$ steps/day & Ref. & & Ref. & & Ref. & & Ref. & \\
\hline$\geq 10,000$ steps/day & 0.99 & {$[0.51,1.98]$} & 0.54 & {$[0.20,1.44]$} & 1.08 & {$[0.53,2.10]$} & 0.49 & {$[0.17,1.40]$} \\
\hline \multicolumn{9}{|l|}{ Parental weight } \\
\hline Non-overweight & & & & & Ref. & & Ref. & \\
\hline Overweight/obesity & & & & & $2.07^{*}$ & {$[1.02,4.19]$} & 1.31 & {$[0.41,4.14]$} \\
\hline Nagelkerke $R^{2}$ & .07 & & .09 & & .10 & & .13 & \\
\hline
\end{tabular}

Note. The binary logistic regression models presented in Table 2 were adjusted for gender and age category of children. $O R=$ odds ratio; $\mathrm{Cl}=$ confidence interval $\mathrm{PA}=$ physical activity; Ref. $=$ reference group; Nagelkerke $R^{2}=$ Nagelkerke coefficient of determination. ${ }^{*} p<.05,{ }^{* *} p<.005$. 
regime for parents, co-creates all-day PA on school/working days similarly for all the participants, but weekend days show a critical decrease in PA, especially among the members of single-child families. A more structured school day/ workday seems to provide both children and parents with better conditions for higher PA than weekends, on which more passive spending of leisure time and longer sleeping are more preferred than on workdays.

As in similar studies from Belarus (Patel et al., 2011), Canada (Bushnik et al., 2017), or the United States of America (Liu et al., 2013), a positive relationship between the BMI of parents and their children, as well as an increased risk of obesity in children in the event of their parents' obesity (Bushnik et al., 2017; Liu et al., 2013; Patel et al., 2011), has been confirmed in both single-child families and families with at least two children. Given the significantly lower likelihood of obesity in children achieving the recommended daily SC regardless of the number of children in the family, sufficient PA is still an effective preventive factor in the development of childhood obesity. Thus, in accordance with a previous study (Sigmundová et al., 2018), weekend days still have underutilized potential for stimulating family PA-enhancing programmes. In addition, family PA enhancement programmes do not necessarily need to be long per occasion but regular and long-term. Even replacing ten minutes of sedentary time in adolescents with ten minutes of moderate-to-vigorous PA (MVPA) daily has a positive effect on waist circumference reduction $(0.5-1 \%)$, and a long-term replacement of $60 \mathrm{~min}$ of sedentary time with MVPA daily exercise can bring the waist circumference reduction up to $3 \mathrm{~cm}$ (Hansen et al., 2018).

Suitable opportunities for the realization of MVPA can be seen in higher levels of participation in organized leisuretime sport or leisure organizations, as most of the children declared no participation in organized leisure-time sport or interest organizations. The use of multiple-purpose sports facilities and centres offering a variety of physical activities for the whole family would be a suitable complement to the increase in habitual PA if there were low admission fees. The results emphasize the need to promote PA-enhancing programmes especially among single-child families. In the case of single-child families, physical activity enhancing programmes with an aspiration to reduce excessive body weight would be encouraged by the participation of all family members, or classmates or neighbourhood children. However, it should be noted that positive parental social control or overall parental support may be ineffective in children with higher BMI who need increasing their PA (Liszewska et al., 2018). In addition, it is also documented that parenting style is associated with childhood obesity authoritarian and negligent parenting are associated with an increased likelihood of childhood obesity (Kakinami et al., 2015), while warm parenting is associated with a decline in or stable child BMI during a family-based weight control programme (Rhee et al., 2016). Therefore, from a public health perspective, it is necessary to shed light on existing parental influences on the incidence of obesity in their offspring, as well as the behaviour of family members participating in family-based energy balance-related programmes.
Although siblings are described as the building blocks of the family structure and the key players in family dynamics (McHale et al., 2012), their role has been relatively neglected in exploring family PA and sedentary behaviour. The results of public health-related research suggest a positive influence of older siblings on the motor development of younger siblings (Hallal et al., 2006; Leonard \& Hill, 2016) and a positive factor of higher weekend MVPA (McMinn et al., 2013). Given the higher level of PA found in families where the children have siblings and the closer linking to the PA of their parents than in single-child families, further studies should illuminate the mediating and moderating mechanisms by which parents may influence sibling PA.

\section{Strengths and limitations of the study}

A major strength of the present study is the involvement of all family members in the all-week monitoring of all-day PA, including school hours, leisure time, and both weekend days.

However, the conclusions of any study need to be formulated in the light of existing methodological limitations. Firstly, a waist-worn spring-suspended pendulum pedometer was used. Although suspended pendulum pedometers are considered to be sufficiently valid to summarize all-day free-living PA optimally during continuous seven-day monitoring (Basett et al., 2017), they are limited when it comes to detecting the intensity or pattern of PA (Rowlands \& Eston, 2007). However, despite PA monitoring constraints, daily SC from a pedometer are a suitable, easily imaginable, and interpretable marker of daily PA, allowing a comparison to be made between children, adolescents, and adults. Although the ideal location for accurate step determination seems to be the ankle or foot, a waist strap-fastened pedometer is accurate enough and can yield useful information on the relationship between daily SC and health outcomes (including body weight; Basett et al., 2017). Secondly, it is necessary to accept the possible influence of social desirability, reactivity, or competitiveness in monitoring the free-living PA of children and adolescents resulting from the display of wearable devices. However, none of the participants was given the cut-off figure of the recommended daily SC, no reactivity was detected on six or more days of PA monitoring (Rowe et al., 2004), and no differences were found in SC measured using sealed and unsealed pedometers (Prewitt et al., 2013). Another limitation is the inability to perform regression analyses with respect to the gender of children or the family structure (father-mother-child together versus parent-child dyads) due to the relatively small size of the only child families, although there are findings pointing to possible gender-specific parent-child PA associations (Sigmundová et al., 2020) or indications of differences in the parent-child excessive body weight relationship with respect to the family structure (Sigmund et al., 2020). The potential limitation could be the home measurement of the body weight and height of family members. However, parental home measurement of children's weight and height according to researchers' instruction sheets is sufficiently accurate compared with 
laboratory measurement (Huybrechts, 2014) for subsequent BMI calculations and the classification of overweight and obesity (Chan et al., 2013), for example according to the WHO percentile growth charts. Moreover, none of the family members was given the cut-off values to classify body weight levels according to the WHO percentile growth (WHO, 2007) charts for the classification of obesity. Although some family-related variables were revealed that may affect the obesity likelihood in children, many other potentially important confounders we have not been able to uncover. Finally, the cross-sectional design of this study does not allow the causality of the parent-child relationships concerning PA or body weight to be ascertained, despite their statistical significance. However, verified theoretical models (Bailey et al., 2015; Davison \& Birch, 2001) indicate the prevailing influence of obesity/PA of parents on their child's obesity/PA, not vice versa.

\section{Conclusions}

Children with siblings reach the recommended amount of daily SC at weekends and on average for the whole week significantly more often and have a lower incidence of overweight and obesity than children from single-child families. Achieving the recommended amount of daily SC in children significantly reduces their likelihood of obesity. Children with siblings have a lower likelihood of obesity than only children, but significantly only in the mother-child model. Maternal overweight/obesity was associated with obesity in the woman's offspring. The results emphasize the need to promote PA-enhancing programmes especially among single-child families. In the case of single-child families, physical activity enhancing programmes with an aspiration to reduce excessive body weight would be encouraged by the participation of all family members, or classmates or neighbourhood children.

\section{Acknowledgments}

This study was supported by the Czech Science Foundation (grant number 19-03276S). The funders had no role in the study design, analysis of the data, decision to publish, or preparation of the study.

\section{Conflict of interest}

The authors report no conflict of interest.

\section{References}

Al-Khudairy, L., Loveman, E., Colquitt, J. L., Mead, E., Johnson, R. E., Fraser, H., Olajide, J., Murphy, M., Velho, R. M., O'Malley, C., Azevedo, L. B., Ells L. J., Metzendorf, M. I., \& Rees, K. (2017). Diet, physical activity and behavioural interventions for the treatment of overweight or obese adolescents aged 12 to 17 years. Cochrane Database of Systematic Reviews, 6, Article CD012691. https://doi.org/10.1002/14651858.CD012691

Appelhans, B. M., Fitzpatrick, S. L., Li, H., Cail, V., Waring, M. E., Schneider, K. L., Whited, M. C., Busch, A. M., \& Pagoto, S. L. (2014). The home environment and childhood obesity in low-income households: Indirect effects via sleep duration and screen time. BMC Public Health, 9(14), Article 1160. https://doi. org/10.1186/1471-2458-14-1160

Bailey, R., Cope, E., \& Parnell, D. (2015). Realising the benefits of sports and physical activity: The Human Capital Model. Retos, 28, 147-154. https://doi. org/10.47197/retos.v0i28.34945
Baranowski, T., Motil, K. J., \& Moreno, J. P. (2019). Multi-etiological perspective on child obesity prevention. Current Nutrition Reports, 8, 1-10. https://doi org/10.1007/s13668-019-0256-3

Basett, D. R., Jr., Toth, L. P., LaMunion, S. R., \& Crouter, S. E. (2017). Step counting: A review of measurement considerations and health-related applications. Sports Medicine, 47(7), 1303-1315. https://doi.org/10.1007/s40279-016-0663-1

Beets, M. W., Brazendale, K., Weaver, R. G., \& Amstrong, B. (2019). Rethinking behavioral approaches to compliment biological advances to understand the etiology, prevention, and treatment of childhood obesity. Childhood Obesity, 15(6), 353-359. https://doi.org/10.1089/chi.2019.0109

Bushnik, T., Garriguet, D., \& Colley, R. (2017). Parent-child association in body weight status. Health Reports, 28(6), 12-19. https://www150.statcan.gc.ca/n1/ pub/82-003-x/2017006/article/14828-eng.htm

Chai, L. K., Collins, C. E., May, C., Holder, C., \& Burrows, T. L. (2019). Accuracy of parent-reported child height and weight and calculated body mass index compared with objectively measured anthropometrics: Secondary analysis of a randomized controlled trial. Journal of Medical Internet Research, 21(9), Article e12532. https://doi.org/10.2196/12532

Chan, N. P. T., Choi, K. C., Nelson, E. A. S., Sung, R. Y. T., Chan, J. C. N., \& Kong, A. P. S. (2013). Self-reported body weight and height: An assessment tool for identifying children with overweight/obesity status and cardiometabolic risk factors clustering. Maternal and Child Health Journal, 17(2), 282-291. https:// doi.org/10.1007/s10995-012-0972-4

Craig, C. L., Cameron, C., \& Tudor-Locke, C. (2013). Relationship between parent and child pedometer-determined physical activity: A sub-study of the CANPLAY surveillance study. International Journal of Behavioral Nutrition and Physical Activity, 10, Article 8. https://doi.org/10.1186/1479-5868-10-8

Danielzik, S., Czerwinski-Mast, M., Langnäse, K., Dilba, B., \& Müller, M. J. (2004). Parental overweight, socioeconomic status and high birth weight are the major determinants of overweight and obesity in 5-7 y-old children: Baseline data of the Kiel Obesity Prevention Study (KOPS). International Journal of Obesity Related Metabolic Disorders, 28(11), 1494-1502. https://doi.org/10.1038/ si.ijo.0802756

Davison, K. K., \& Birch, L. L. (2001). Childhood overweight: A contextual model and recommendations for future research. Obesity Reviews, 2(3), 159-171. https://doi.org/10.1046/i.1467-789x.2001.00036.x

de Onis, M., Onyango, A. W., Borghi, E., Siyam, A., Nishida, C., \& Siekmann, J. (2007). Development of a WHO growth reference for school-aged children and adolescents. Bulletin of the World Health Organization, 85(9), 660-667. https:// doi.org/10.2471/blt.07.043497

Glinianaia, S., Rankin, J., Pless-Mulloli, T., Pearce, M. S., Charlton, M., \& Parker, L. (2008). Temporal changes in key maternal and fetal factors affecting birth outcomes: A 32-year population-based study in an industrial city. BMC Pregnancy and Childbirth, 19(8), Article 39. https://doi.org/10.1186/1471-2393-8-39

Hallal, P. C., Wells, J. C. K., Reichert, F. F., Anselmi, L., \& Victoria, C. G. (2006). Early determinants of physical activity in adolescence: Prospective birth cohort study. BMJ, 332(7548), 1002-1007. https://doi.org/10.1136/bmj.38776.434560.7C

Hansen, B. H., Andersen, S. A., Andersen, L. B., Hildebrand, M., Kolle, E., SteeneJohannessen, J., Kriemler, S., Page, A. S., Puder, J. J., Reilly, J. J., Sardinha, L. B., van Sluijs, E. M. F., Wedderkopp, N., \& Ekelund, U. (2018). Cross-sectional associations of reallocating time between sedentary and active behaviours on cardiometabolic risk factors in young people: An international children's accelerometry database (ICAD) analysis. Sports Medicine, 48(10), 2401-2412. https://doi.org/10.1007/s40279-018-0909-1

Hašková, H., Dudová, R., \& Pospiśilová, K. (2019). Kde se berou jedináčci? Faktory související s jednodětností v ČR [Why an only child? Factors connected with having a single child in the CR]. Demografie, 61(2), 93-110. https://www.czso. cz/documents/10180/91917740/13005319q2 93.pdf/7a9600c3-4d96-43c8-b435-3215 d73a6031?version $=1.0$

Huybrechts, I., Beirlaen, C., De Vriendt, T., Slimani, N., Pisa, T. P., Schouppe, E., De Coene, A., De Bacquer, D., De Henauw, S., \& Himes, J. H. (2014). Validity of instruction leaflets for parents to measure their child's weight and height at home: Results obtained from a randomised controlled trial. BMJ Open, 4(2), Article 003768. https://doi.org/10.1136/bmiopen-2013-003768

Kakinami, L., Barnett, T. A., Séguin, L., \& Paradis, G. (2015). Parenting style and obesity risk in children. Preventive Medicine, 75, 18-22. https://doi.org/10.1016/i. ypmed.2015.03.005

Kooiman, T. J. M., Dontje, M., Sprenger, S. R., Krijnen, W. P., van der Schans, C. P., \& de Groot, M. (2015). Reliability and validity of ten consumer activity trackers. BMC Sports Science, Medicine \& Rehabilitation, 7, Article 24. https://doi. org/10.1186/s13102-015-0018-5

Kumar, S., \& Kelly, A. S. (2017). Review of childhood obesity: From epidemiology, etiology, and comorbidities to clinical assessment and treatment. Mayo Clinic Proceedings, 92(2), 251-265. https://doi.org/10.1016/i.mayocp.2016.09.017

Leonard, H. C., \& Hill, E. L. (2016). The role of older siblings in infant motor development. Journal of Experimental Child Psychology, 152, 318-326. https://doi. org/10.1016/i.jecp.2016.08.008

Liszewska, N., Scholz, U., Radtke, T., Horodyska, K., Liszewski, M., \& Luszczynska, A. (2018). Association between children's physical activity and parental practices enhancing children's physical activity: The moderating effects of children's BMI z-score. Frontiers in Psychology, 8, Article 2359. https://doi. org/10.3389/fpsyg.2017.02359 
Liu, Y., Chen, H. J., Liang, L., \& Wang, Y. (2013). Parent-child resemblance in weight status and its correlates in the United States. PLOS ONE, 8(6), Article e65361. https://doi.org/10.1371/journal.pone.0065361

McHale, M. S., Updegraff, K. A., \& Whiteman, S. D. (2012). Sibling relationships and influences in childhood and adolescence. Journal of Marriage and the Family, 74(5), 913-930. https://doi.org/10.111/j.1741-3737.2012.01011.x

McMinn, A. M., Griffin, S. J., Jones, A. P., \& van Sluijs, E. M. F. (2013). Family and home influences on children's after-school and weekend physical activity. European Journal of Public Health, 23(5), 805-810. https://doi.org/10.1093/ eurpub/cks160

Mead, E., Brown, T., Rees, K., Azevedo, L. B., Whitaker, V., Jones, D., Olajide, J. Mainardi, G. M., Corpeleijn, E., O'Malley, C., Beardsmore, E., Al-Khudairy, L., Baur, L., Metzendorf, M.-I., Demaio, A., \& Ells, L. J. (2017). Diet, physical activity and behavioural interventions for the treatment of overweight or obese children from the age of 6 to 11 years. Cochrane Database of Systematic Reviews, 6, Article CD012651. https://doi.org/10.1002/14651858.CD012651

Parks, E. P., Kumanyika, S., Moore, R. H., Stettler, N., Wrotniak, B. H., \& Kazak, A. (2012). Influence of stress in parents on child obesity and related behaviors. Pediatrics, 130(5), e1096-e1104. https://doi.org/10.1542/peds.2012-0895

Patel, R., Martin, R. M., Kramer, M. S., Oken, E., Bogdanovich, N., Matush, L., Smith, G. D., \& Lawlor, D. A. (2011). Familial associations of adiposity: Findings from a cross-sectional study of 12,181 parental-offspring trios from Belarus. PLOS ONE, 6(1), Article e14607. https://doi.org/10.1371/journal.pone.0014607

Prewitt, S. L., Hannon, J. C., \& Brusseau, T. A. (2013). Children and pedometers: A study in reactivity and knowledge. International Journal of Exercise Science, 6(3), 230-235. https://digitalcommons.wku.edu/iies/vol6/iss3/6

Rhee, K. E., Jelalian, E., Boutelle, K., Dickstein, S., Seifer, R., \& Wing, R. (2016) Warm parenting associated with decreasing or stable child BMI during treatment. Childhood Obesity, 12(2), 94-102. https://doi.org/10.1089/chi.2015.0127

Rojičcek, M., Boušková, M., Elischer, D., Ernest, J., Holý, D., Hrbek, J., Hronza, M. Kermiet, V., Král, K., Krumpová, E.., Kuncová, P.., Lojka, J., Mana, M. Matějka, R., Mrázek, J., Novotný, M., Polednová, Z., Rybáček, V., Sixta, J., ... Zelený, M. (2019). Statistical yearbook of the Czech Republic - 2019. Czech Statistical Office. https://www.czso.cz/csu/czso/statistical-yearbook-of-the-czech-republic-2019

Rowe, D. A., Mahar, M. T., Raedeke, T. D., \& Lore, J. (2004). Measuring physical activity in children, with pedometers: Reliability, reactivity, and replacement of missing data. Pediatric Exercise Science, 16(4), 343-354. https://doi.org/10.1123/ pes.16.4.343

Rowlands, A. V, \& Eston, R. G. (2007). The measurement and interpretation of children's physical activity. Journal of Sports Science \& Medicine, 6(3), 270276. https://www.jssm.org/issm-06-270.xml>Fulltext

Sigmund, E., \& Sigmundová, D. (2017). Parent-child physical activity, sedentary behaviour, and obesity. Palacký University Olomouc. https://doi.org/10.5507/ ftk.17.24451824

Sigmund, E., Sigmundová, D., \& Badura, P. (2020). Excessive body weight of children and adolescents in the spotlight of their parents' overweight and obesity, physical activity, and screen time. International Journal of Public Health, 65(8), 1309-1317. https://doi.org/10.1046/i.1467-789x.2001.00036.x

Sigmundová, D., Badura, P., Sigmund, E., \& Bucksch, J. (2018). Weekday-week end variations in mother-/father-child physical activity and screen time relationship: A cross-sectional study in a random sample of Czech families with 5 to 12-year-old children. European Journal of Sport Science, 18(8), 1158-1167. https://doi.org/10.1080/17461391.2018.1474951

Sigmundová, D., Sigmund, E., Badura, P., \& Hollein, T. (2020). Parent-child physical activity association in families with 4- to 16-year-old children. Internationa Journal of Environmental Research and Public Health, 17(11), Article 4015. https://doi.org/10.3390/ijerph17114015

Tudor-Locke, C., Craig, C., Beets, M. W., Belton, S., Cardon, G. M., Duncan, S., Hatano, Y., Lubans, D. R., Olds, T. S., Raustorp, A., Rowe, D. A., Spence, J. C., Tanaka, S., \& Blair, S. N. (2011). How many steps/day are enough? for children and adolescents. International Journal of Behavioral Nutrition and Physical Activity, 8, Article 78. https://doi.org/10.1186/1479-5868-8-78

Tudor-Locke, C., Craig, C., Brown, W., Clemes, S., De Cocker, K., Giles-Corti, B., Hatano, Y., Inoue, S, Matsudo, S. M., Mutrie, N., Oppert, J-M., Rowe, D. A Schmidt, M. D., Schofield, G. M., Spence, J. C., Teixeira, P. J., Tully, M. A., \& Blair, S. N. (2011). How many steps/day are enough? for adults. International Journal of Behavioral Nutrition and Physical Activity, 8, Article 79. https://doi. org/10.1186/1479-5868-8-79

World Health Organization. (2007). Growth reference data for 5-19 years. WHO Reference 2007. https://www.who.int/toolkits/growth-reference-data-for-5to19-years World Health Organization. (2014). Obesity and overweight. Fact sheet $\mathrm{No}^{\circ} 311$. https://www.who.int/mediacentre/factsheets/fs311/en 